\title{
Laertes e o mundo do trabalho na Odisseia
}

\author{
Adriane da Silva Duarte \\ Universidade de São Paulo \\ asduarte@usp.br
}

\begin{abstract}
Odysseus establishes several alliances to fight Penelope's suitors in order to reassume his place at Ithaca. These alliances are marked by work. Humble workers (like Eumaeus, Philoetius, Eurycleia) stand side by side the hero's wife, Penelope, the weaver. All this activity contrasts with the suitors' idleness, constantly consuming the products of other people's work. One of the last recognition scenes of the poem, in which the hero is recognized by his father, Laertes (Od., XXIV 205-360), reaffirms work's special place at Odysseus' relationships and strategies. This paper intends to examine this scene and discuss its meaning to the major context of the Odyssey.

KEYWORDS: Homer; Odyssey; Laertes; work; recognition scenes.
\end{abstract}

"The whole country estate of Laertes showcases a world of application to work in a particular realm". 1

O retorno de Odisseu a Ítaca é marcado pela realização de uma série de alianças que cumprem uma dupla função. De um lado, o herói obtém apoio necessário para enfrentar um número desproporcional de adversários; de outro, através de cada um destes contatos, é reconhecido socialmente, voltando a ocupar um papel de direito do qual fora temporariamente alijado - volta a ser pai quando Telêmaco o reconhece (XVI 154-219); senhor, ao ter sua identidade revelada a Euricleia, Eumeu e Filécio (XIX 290327; XXI 188-244); marido, ao ser reconhecido por Penélope (XXIII 1-240); filho e legítimo sucessor ao poder, após seu encontro com Laertes (XXIV 205-348) e soberano de Ítaca, após os confrontos finais com os pretendentes e suas famílias (XXII 1-41; XXIV 413-548). ${ }^{2}$

Um exame dessas relações mostra que o mundo do trabalho permeia praticamente todas as alianças que o herói estabelece. Odisseu cerca-se de trabalhadores, por vezes humildes, como o porqueiro Eumeu, o cabreiro Filécio ou a criada Euricleia, mas também entre seus familiares encontram-se trabalhadores. Penélope é exímia tecelã e Laertes hábil agricultor - até mesmo Argos, o cão do herói, é

\footnotetext{
${ }^{1}$ Cf. Henderson, J. The name of the tree: recounting Odyssey XXIV 340-2. Journal of Hellenic studies. London, vol. CXVII, p. 99, 1997: "Toda propriedade rural de Laertes demonstra um mundo de dedicação ao trabalho em um reino particular" (tradução da autora).

${ }^{2}$ Cf. Goldhill, S. The poet hero: language and representation in the Odyssey. In: Goldhill, S. The poet's voice. Essays on poetics and Greek literature. Cambridge: University Press, 1991, p. 1-68; Murnaghan, S. Disguise and recognition in the Odyssey. Princeton: Princeton University Press, 1984.
} 
descrito por sua habilidade na caça, não como animal de exibição. ${ }^{3}$ É como se Odisseu firmasse uma aliança pelo trabalho, capaz de antepor-se à ociosidade que caracteriza os pretendentes, entregues ao consumo contumaz do fruto do trabalho alheio. É verdade que o ultraje representado pela presença dos pretendentes na casa de Odisseu deve-se menos ao ócio do que ao desrespeito das normas que regem a hospitalidade no mundo antigo, já que desfrutam dela sem oferecer a contrapartida necessária. Ainda assim, é claro o contraste entre esses dois grupos, a família do herói e seus agregados, e os pretendentes, no que tange a atividade produtiva e nos diz algo sobre a organização social na Odisseia.

No entanto, não se deve concluir a partir disso que os gregos valorizassem o trabalho por si só. Como Hesíodo enfaticamente lembra, o trabalho é uma necessidade imposta aos homens pelos deuses e constitui uma marca de separação entre uns e outros - o mito de Pandora e o das raças ilustra bem esta ideia ao evocar um passado em que a terra produzia por si só e os homens viviam fartamente. Embora Hesíodo aconselhe vivamente seu irmão Perses a se dedicar ao trabalho, um mal necessário, Finley observa que, nos poemas homéricos, "o juízo moral que a sociedade fazia do trabalho não se dirigia ao próprio ato mas à pessoa e às circunstâncias". ${ }^{4}$ Assim, ele prossegue, embora Odisseu fosse capaz de construir uma jangada ou cuidar de um rebanho, não se esperava que ele se ocupasse de tais atividades, a não ser como forma de lazer, ou seja, no exercício do ócio. Conclui Finley (1982: 68-69):

Era essa a grande linha de demarcação entre os que eram constrangidos ao trabalho e os que não eram.

Um dos últimos reconhecimentos do herói, o de seu pai Laertes (Od. XXIV 205360), reafirma o lugar privilegiado do trabalho nas relações e nas estratégias por ele

\footnotetext{
${ }^{3}$ Cf. Scodel, R. Odysseus' dog and the productive household. Hermes. Wiesbaden, vol. CXXXIII/ CXXXIV, p. 403, 2005: Argus was not reared for luxury, but as hunting dog. The narrative has already presented both the suitors' waste of Odysseus property and Eumaeus' efforts to increase his master's wealth. Odysseus here adumbrates, at the moment he is about to re-enter his house, a particular refinement of this contrast: the suitors and those of the household with side with them are luxurious spenders of goods in conspicuous consumption, while Odysseus and his family increase their wealth rather than display it ("Argos não foi criado por luxo, mas como cão de caça. A narrativa já havia apresentado tanto a dilapidação dos bens de Odisseu pelos pretendentes quanto os esforços de Eumeu para incrementar a riqueza de seu patrão. Prestes a fazer sua re-entrada em sua casa, Odisseu prefigura um refinamento particular desse contraste: os pretendentes, e os criados que se alinham com eles, são luxuriantes gastadores de bens num consumo conspícuo enquanto Odisseu e sua família incrementam sua riqueza em vez de exibi-la").

${ }^{4}$ Cf. Finley, M. I. O mundo de Ulisses. Tradução de Armando Cerqueira. Lisboa: Editorial Presença, 1982 , p. 68.
} 
adotadas, ainda que nos permita avaliar de fato seu alcance. Desta vez, a aproximação do pai consolida também a reapropriação da terra-mãe, a cujo cultivo Laertes se dedica. Esse interesse do velho nobre pela terra não é recente, pois, o poeta nos diz que a propriedade fora há muito adquirida (XXIV 206) e o próprio Odisseu recorda suas excursões infantis no pomar paterno (XXIV 335-344).

No entanto, a situação em que Laertes se encontra ao início do poema parece ser excepcional. Já no canto I, Mentes comenta a sua reclusão no campo, acompanhado apenas por uma velha criada (I 189-193). No encontro com sua mãe no Hades, Odisseu ouve o relato do estado de penúria e sofrimento em que Laertes se encontra (XI 187196). Veste-se com farrapos e dorme sem cobertas, ora junto às cinzas com os empregados, ora ao ar-livre, no "monstruoso terreno em que tem sua vinha plantada" (I

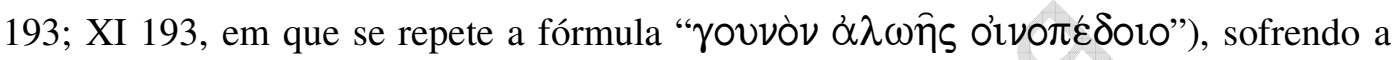
ausência do filho. A dor a que se entrega o patriarca é acentuada pela súbita viagem de Telêmaco, que, como atesta Eumeu, o lança num estado de profunda inércia, "não come nem bebe, nem inspeciona os trabalhos" (XVI 143-144:

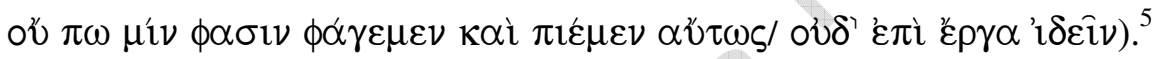

A excepcionalidade da situação de Laertes está, por um lado, na opção de expressar a sua dor fisicamente, abrindo mão da vida suntuosa que se levava no palácio para adotar a pobreza do camponês que se esfalfa nos trabalhos da terra. Embora Eumeu restrinja as atividades do velho senhor à supervisão do trabalho de servos e escravos, Odisseu vai encontrá-lo em plena lide (XXIV 226ss.), situação que bem se poderia depreender da observação de Anticleia de que o marido dormia e fazia as refeições com os empregados - daí, trabalhar ombro a ombro com eles ser provável consequência (XI 187ss.). O caso de Laertes ilustra os dois sentidos do substantivo $\pi$ óvos: trabalho fatigante e sofrimento moral.

Por outro lado, chama a atenção a sua retirada da vida pública. Mentes observa que ele "não mais a cidade procura e frequenta" (I 189-190:

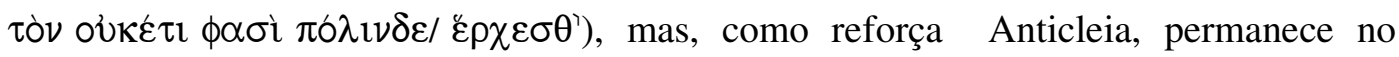
campo, "sem baixar nunca à cidade" (XI 187-188:

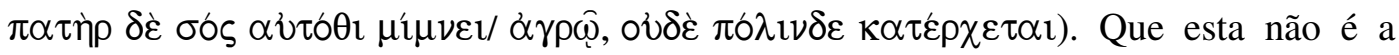
atitude esperada de uma pessoa de sua condição é evidente pelo contraste com Nestor,

\footnotetext{
${ }^{5}$ As citações da Odisseia seguem a tradução de Carlos Alberto Nunes: Homero. Odisseia. Tradução de Carlos Alberto Nunes. São Paulo: Ediouro, 1997.
} 
que, a despeito da idade, oficia os sacrifícios e recebe os hóspedes em Pilos, exercendo uma função pública e de autoridade (Od. III). ${ }^{6}$

Apesar de ter sido informado (por Anticleia, por Eumeu) do estado em que vivia seu pai, Odisseu parece chocado ao avistá-lo trabalhando a terra (XXIV 226-234, tradução de Carlos Alberto Nunes):

Foi, pois, o pai encontrar no pomar bem plantado, sozinho, a mondar ervas em volta de uma árvore; estava vestido com roupas velhas e sujas, e em torno das pernas polainas de couro grosso de boi, proteção natural contra espinhos, nas mãos luvas, também, por defesa. De pele de cabra traz, afinal, um barrete, que mais lhe acentuava a miséria. Quando o divino e sofrido Odisseu o avistou desse modo, pela velhice alquebrado, a sofrer em seu peito grande dor, postou-se, então, a chorar junto ao tronco de uma alta pereira. ${ }^{7}$

Cabe aqui fazer um parêntese para notar que a manutenção do pomar de Laertes requer bastante trabalho. Além dele próprio, um criado leal, Dólio, e seus filhos ajudamno nas muitas tarefas, listadas ao longo do canto XXIV: cortar espinheiros (v. 224), prover as mudas com estacas ou cercas de proteção (v. 225), arrancar ervas daninhas (v. 226), afofar a terra ao redor das plantas (v. 242). Com certeza Laertes não concordaria com a observação de Vernant e Vidal-Naquet (apud Jeanmaire) sobre a arboricultura demandar pouco ou nenhum trabalho em contraste a cultura de grãos. O pai de Odisseu não parece confiar apenas aos deuses à manutenção de seu belo pomar, mas se aplica a ela continuamente para ter a certeza de poder colher os frutos. ${ }^{8}$

Embora o herói parecesse mais abalado com o aspecto de seu pai, a impressão geral deriva da atividade que então exercia no pomar. O poeta mesmo nos diz que o barrete usado por Laertes no trabalho "acentuava sua miséria" - note-se que o termo grego é $\pi \varepsilon v \theta \circ \varsigma$, e que a veste indica antes a dor que a penúria. Ou seja, a veste surrada

\footnotetext{
${ }^{6}$ Não vou discutir as razões de Laertes não retomar a autoridade política após a partida do filho. Remeto, no entanto, para as observações de Finley (1982: 82-83).

${ }^{7}$ Está em itálico a correção de um cochilo do tradutor, que atribuiu ao filho a dor que o pai sentia (v. 233: Quando Odisseu o avistou alquebrado pela velhice, "sentiu confranger-se-lhe o peito. Posta-se...etc" para

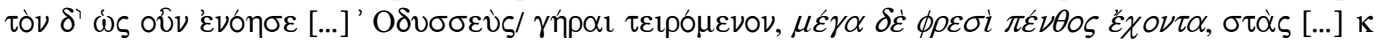
$\alpha \grave{\imath} \varepsilon \hat{i} \beta \varepsilon)$.

${ }^{8}$ Cf. Vernant, J.-P.; Vidal-Naquet, P. Trabalho e natureza na Grécia antiga. In: Trabalho e escravidão na Grécia Antiga. Tradução de Marina Appenzeller. Campinas: Papirus, 1989, especialmente, p. 11-12: A arboricultora prolonga a economia da colheita: seus produtos aparecem como dons da natureza, bênçãos que são atribuídas a divindades que dispensam riqueza [...]. Sua função é fazer os ramos crescerem e desabrocharem os frutos, de acordo com o ritmo das estações dos quais o homem participa menos pelo seu trabalho do que pela realização periódica de festas e festins que promovem a comunhão com os deuses.
} 
usada no trabalho inspira piedade, como deveria inspirá-la as vestes esfarrapadas dos reis que Eurípides punha em cena em suas tragédias. ${ }^{9}$ Assim, os estados de alma e o físico são indissociáveis e, com sua opção pelo trabalho, Laertes parece reforçar isso.

O impacto causado pela visão paterna não basta para dissuadir Odisseu de ocultar sua identidade e testar seu pai, como antes testara outros parentes e aliados. Essa decisão tem provocado um vívido debate entre os comentadores do poema que discutem as razões de o herói submeter seu pai a tal carga emocional, sobretudo após afastada a ameaça representada pelos pretendentes e da lealdade do velho senhor ter sido atestada anteriormente em várias oportunidades - como nos testemunhos de Anticleia e de Eumeu aqui citados. Há quem julgue toda a passagem suspeita e há quem busque justificar a atitude supostamente cruel do herói argumentando, essencialmente, em duas direções. ${ }^{10}$

Julgando que a idade avançada e a fragilidade de seu estado emocional fossem fatores de risco de vida, caso Laertes fosse abruptamente informado da volta do filho, Odisseu adota esta estratégia de aproximação como forma de produzir um choque capaz de tirar seu pai do estado de extrema fragilidade e letargia em que se encontrava (catarse) e poder contar com ele na disputa que se seguiria contra a família dos mortos. Richardson (1983: 227-228) cita diversas fontes antigas que associam a condição de Laertes a do cão Argos, cuja morte é entendida como decorrente da experiência de uma emoção extrema, o prazer de ver seu dono de volta a casa. O cão teria morrido de alegria e, para evitar que o mesmo acontecesse a Laertes, Odisseu mente sobre sua identidade, até perceber que a tristeza extrema poderia também ser fatal. Após ouvir do estrangeiro que era provável que seu filho estivesse morto, a reação do ancião é (XXIV 315-317):

[...] uma nuvem sombria de dor a Laertes cobriu; e, tendo terra anegrada tomado nas mãos, derramou-a na veneranda cabeça, a soltar incessantes gemidos.

\footnotetext{
${ }^{9}$ Ao menos é o que Aristófanes sugere ao fazer Diceópolis visitar a casa de Eurípides em busca de um figurino que impactasse o coro de Acarnenses na comédia homônima. Note-se que Anticleia já havia

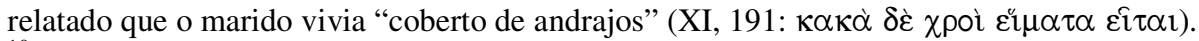

${ }^{10}$ Sobre está questão, cf. balanço crítico de Scodel, R. The removal of the arms, the recognition with Laertes, and narrative tension in the "Odyssey". Classical philology. Chicago, vol. XCIII, n. 1, p. 9-10, 1998. Cf. também observações de Richardson, N. J. Recognition scenes in the "Odyssey" and ancient literary criticism. In: Cairns, F. (org.). Papers of the Liverpool Latin seminar. Liverpool, vol. IV, p. 227229, 1983.
} 
Já para outros, Odisseu assim age porque o modo de ser astucioso faz parte de sua natureza, de modo que a própria abordagem constitui a primeira prova de identidade oferecida ao pai.

Seja como for, o herói aproxima-se do pai sem ser notado, enquanto ele, absorto, "se encontrava abaixado, a cavar ao redor de um arbusto" (XXIV 241), e lhe diz (XXIV 244-257):

Vejo, meu velho, que tens muito jeito para essa labuta de pomareiro, pois tudo está feito com senso e capricho, sem que as pereiras e as vides, os pés de oliveira, as figueiras e as plantações de legumes pereçam por falta de trato. Ora outra coisa vou te perguntar, sem com isso, ofender-te. Não tens contigo o cuidado preciso, que além da velhice que te acabrunha, andas sujo e vestido de modo indecente. Não há de ser por preguiça [tua] que assim te maltrata o teu [amo, pois não se nota, na altura e no aspecto, que tens natureza de vil escravo; antes mostras possuir majestade de chefe. Ora, aos senhores compete, depois de banhado e almoçado, em bons colchões repousar. Esse é o jus da velhice pacata. Vamos, agora me fala e responde conforme a verdade: Como se chama teu amo? De quem é o pomar que cultivas?

Como já apontou Scodel (1983: 12), esta fala se divide claramente em duas partes: o elogio ao pomar (v. 244-247) e a censura ao pomareiro (248-255). Ambos

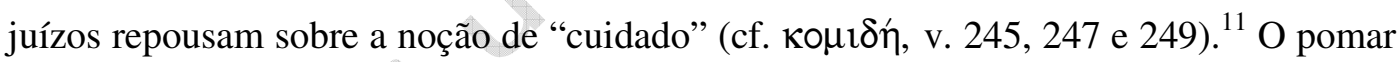
está bem cuidado, cada planta floresce por bem tratada. O pomareiro, ao contrário, demonstra descuido com sua aparência, veste-se de modo incompatível com a sua condição, o que ressalta sua velhice - o termo velho ou velhice ocorre nesta passagem

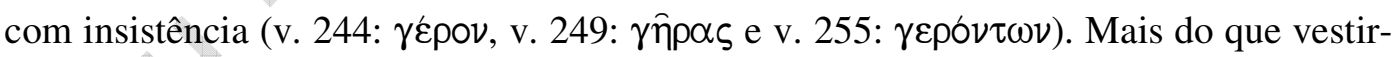
se de forma inadequada, Laertes age de forma incompatível com sua idade e estatuto social. Vidal-Naquet, ao analisar esta passagem, observa:

Essa miséria choca Ulisses: "Não há nada em ti que denote um escravo, nem a estatura, nem o aspecto: tens mais o ar de um rei". Ulisses fica ainda mais espantado ao ver que esse nobre ancião trabalha: o trabalho não é uma virtude real no mundo homérico e a velhice é tempo de repouso. ${ }^{12}$

\footnotetext{
${ }^{11}$ Cf. Henderson (1997: 97).

${ }^{12}$ Cf. Vidal-Naquet, P. O mundo de Homero. Tradução de Jônatas Batista Neto. São Paulo: Companhia das Letras, 2000, p. 103. Os versos parafraseados pertencem ao canto XXIV, 252-253. O termo "real"
} 
De fato a fala de Odisseu é clara: aos senhores convém descansar, isso é o

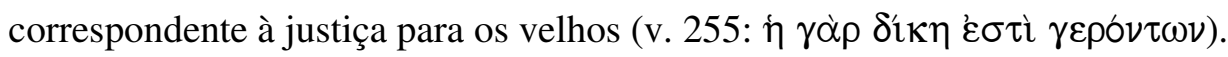

Apesar de notar-lhe o porte nobre, Odisseu, com intuito claramente provocativo, somadas a atitude e a aparência do velho, o trata como um escravo (v. 257, $\delta \mu \omega ́ \varsigma)$ e lhe pede informações sobre seu patrão, apresentando-se como um abastado anfitrião de Odisseu, cinco anos atrás. Informado da ausência do herói, dá a entender que o julga morto, pois sua partida fora auspiciosa, nenhum obstáculo se fazendo prever a um retorno tranquilo. Como nota Scodel (1983: 13), longe de se indignar com o juízo errôneo que o estrangeiro faz a seu respeito, Laertes revela toda sua dor, advinda da suposição da morte do filho:

He seems certain that Odysseus has died, and is certain that the stranger has wasted his gifts, since Odysseus cannot offer any return. He thereby emphatically fails to respond to Odysseus' invitations to behave in accordance with his status, for he is not offended at being mistaken for a slave, nor does he offer any hospitality. ${ }^{13}$

Ou seja, se a intenção de Odisseu era produzir um choque que fizesse o pai recuperar a dignidade perdida, o teste não produz o resultado almejado, mas apenas aumenta a fragilidade do velho senhor.

Nesse momento, comovido pelo estado em que seu pai se encontra, o herói resolve revelar sua identidade e o destino dos pretendentes. Mas agora é a vez de Laertes mostrar-se cético e pedir um "sinal evidente", capaz de convencê-lo.

Odisseu oferece duas provas de identidade: a cicatriz deixada pelo javali que o atacara nos domínios de seu avô materno, no Parnaso (v. 331), sinal que já exibira antes com maior ou menor sucesso a Eumeu, Filécio, Euricleia e Penélope, e a indicação das árvores que seu pai lhe ofertara naquele mesmo pomar, quando ele era criança (v.335). Diz o herói (v. 335-344):

\section{Posso apontar-te também, no teu belo pomar as fruteiras}

está em itálico porque é ambíguo em português, remetendo tanto ao que é próprio de rei quanto ao que tem existência concreta. Independentemente de qual seja a palavra francesa empregada, ambas as interpretações se sustentam nesse contexto.

13 "Ele aparenta ter certeza da morte de Odisseu e de que o estrangeiro presenteou-o em vão, já que Odisseu já não pode lhe retribuir. Por isso ele reluta em corresponder aos convites de Odisseu para comportar-se de acordo com seu status, não por estar ofendido por ser tomado por um escravo, e nem oferece hospitalidade" (tradução da autora). 
que, certa vez, me ofertaste. Pedia-te todas as coisas, pois muito criança então era, ao passearmos pelo horto

[variado,

em meio às árvores. Tu me dizias os nomes de todas. Treze pereiras, então, com mais dez macieiras me deste, e mais quarenta figueiras. Disseste, também, que darias renques de cepas cinquenta, que frutos todos os anos [produzem uvas de todas as castas, por isso pendentes se vêem quando as sazões de Zeus grande oportunas sobre elas baixassem.

Assim, o herói faz do pomar, cenário da cena de reconhecimento, uma prova de sua identidade. Mais ainda, este é o sinal decisivo, que contribui para a reconstituição dos laços que unem pai e filho, pois traz à tona memórias de sua convivência passada, interrompida por uma separação de vinte anos. Uma memória tão forte que Laertes encerra-se nela para não perder contato de vez com o filho - talvez esteja aí a explicação para o seu retiro campestre.

Pode-se pensar também que o pomar que Laertes cultiva com tanto esmero é um símbolo de continuidade da família. A resposta do ancião à desordem instaurada pelos pretendentes na casa da cidade é o seu bem cuidado pomar, que um dia será herdado por seu único filho, a quem ele já havia presenteado com treze pereiras, dez macieiras, quarenta figueiras e cinquenta parreiras. Garantir que esta propriedade seja passada à próxima geração é, de certa forma, assegurar a posse da terra para sua família. Nesse sentido, Laertes trabalha para que sua semente prospere. É significativo, portanto, que ao aceitar como prova suficiente o sinal das árvores, o pai o tenha denominado

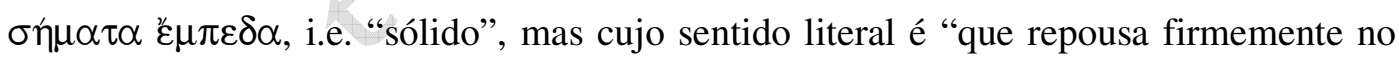
solo" ( $\varepsilon \nu \pi \varepsilon \delta \delta \nu)$, que está enraizado. John Henderson (1997: 100), em seu belo ensaio dedicado ao encontro entre pai e filho na Odisseia, observa que:

What Laertes gave Odysseus was a gift, a promise, a script and a pledge. His life was to be spent realizing the estate so that he would yield the patrimony as stipulated in advance. The trees would live. They would flourish. Laertes would see they kept their seasonal calendar through the years, lived up to the conditions, responded to loving care, and, before all, were there. They were there, always waiting Odysseus, bringing him back home, determining his objectives and ordering his priorities, his pre-destination and promised land. Fruitful and deep-rooted caring, the gardener's jolly world: the orchard-story, with his evocation of the youth of the trees 


\title{
nuntius antiquus
}

that are still surrounding the speaker, tells of continuity and endurance. $^{14}$

É possível interpretar a florescência do pomar como um sinal de favor divino. Hesíodo, em Os trabalhos e os dias (v. 225-237), descreve como as virtudes do rei justo são recompensadas pelos deuses com a fertilidade da terra e dos rebanhos e a prosperidade da população. O pomar de Laertes simboliza sua autoridade moral e sinaliza que os deuses reconhecem o direito de mando dele e de sua família. É significativo que o velho aponte em sua primeira fala ao filho após o reconhecimento sua certeza da participação dos deuses na punição aos pretendentes (XXIV 351-352):

Deuses eternos, Zeus pai, ainda existem no Olimpo muito amplo, se os pretendentes, de fato, pagaram seus atos iníquos.

Reconhecer o filho é reconhecer-se pai deste filho e, portanto, recuperar a dignidade perdida. O retorno do filho, seu herdeiro, o continuador do génos, põe fim a sua obra. O pai do chefe, do senhor da ilha, pode enfim abandonar a lide, banhar-se e vestir-se adequadamente, levando a vida que "convém aos velhos". Assim, concluído o reconhecimento, Laertes e Odisseu se dirigem a casa da propriedade para que o pai receba os cuidados que antes evitara. O poeta nos informa que (v. 365-371):

\begin{abstract}
Dentro de casa, entrementes, a anciã Siciliana banhava o velho Laertes magnânimo e o ungia com óleo finíssimo, num belo manto envolvendo-o depois. A donzela de Zeus aproximou-se e vigor insuflou no pastor de guerreiros, forte e mais alto do que antes e digno de ver o deixando. Findo isso tudo, saiu da banheira. Odisseu admirou-se por ver que aos deuses eternos na forma exterior semelhava.
\end{abstract}

Atena submete Laertes ao sopro revigorante, que faz renascer nele o ímpeto guerreiro há muito perdido. De fato, o velho senhor se vangloria de seus feitos

\footnotetext{
14 “O que Laertes deu a Odisseu foi um dom, uma promessa, um roteiro e um compromisso. Sua vida era para ser gasta dando forma à propriedade de modo que ele produzisse o patrimônio estipulado antecipadamente. As árvores deveriam viver. Elas deveriam florescer. Laertes as veria manter seu calendário sazonal através dos anos, avivadas pelas circunstâncias, reagindo ao cuidado carinhoso, e, sobretudo, estando ali. Elas estavam ali, esperando sempre por Odisseu, trazendo-o de volta para casa, determinando seus objetivos e traçando suas prioridades, [eram] sua predestinação e sua terra prometida. Cuidado frutífero e enraizado, o mundo alegre do jardineiro: o pomar-história, com sua evocação da juventude das árvores que ainda rodeiam o falante, conta de continuidade e de resistência" (tradução da autora). Pode-se dizer que a atividade agrícola de Laertes, que se faz em função da expectativa do retorno do filho, corresponde à tecelagem de Penélope. Seu estratagema é adiar com seu trabalho as núpcias iminentes, na expectativa que Odisseu regresse e restaure a normalidade social em Ítaca.
} 
guerreiros na campanha dos Cefalênios contra Nérico e chega a afirmar que não teria feito feio frente aos pretendentes, se ao lado do filho tivesse tido oportunidade de lutar (v. 375-382). Essa transformação no ânimo e no físico de Laertes é importante, já que antecede o enfrentamento com os parentes dos pretendentes mortos, do qual ele participará ao lado de seu filho e neto, selando definitivamente a reunião da família e sua recondução ao comando.

Ao final do poema, Laertes abandona os trabalhos do lavrador para abraçar os do guerreiro. Homero aplica o mesmo termo a ambas as atividades: ع $\rho^{\prime} \gamma \alpha$. Só que elas são incompatíveis entre si, como também o demonstra Hesíodo no seu mito das raças ( $O s$ trabalhos e os dias, v. 106ss.). O trabalho de Laertes no campo é consequência do despojamento de sua verdadeira condição - assim como Odisseu teve que levar uma vida de mendigo até recuperar a sua. Uma vez recuperada, ele pode assumir outros trabalhos, e outros ócios, mais condizentes com o papel que ocupa na sociedade. ${ }^{15}$

\section{Referências}

FINLEY, M. I. O mundo de Ulisses. Tradução de Armando Cerqueira. Lisboa: Presença, 1982.

GOLDHILL, S. The poet hero: language and representation in the Odyssey. In: Goldhill, S. The poet's voice. Essays on poetics and Greek literature. Cambridge: University Press, 1991.

HENDERSON, J. The name of the tree: recounting Odyssey XXIV 340-2. Journal of Hellenic studies. London, vol. CXVII, p. 87-116, 1997.

HOMER. The Odyssey. Greek text with an English translation by A. T. Murray. Cambridge/Mass.: Harvard University Press, 1984.

. Odisseia. Tradução de Carlos Alberto Nunes. São Paulo: Ediouro, 1997.

RICHARDSON, N. J. Recognition scenes in the "Odyssey" and ancient literary criticism. In: CAIRNS, F. (org.). Papers of the Liverpool Latin seminar. Liverpool, vol. IV, p. 219-235, 1983.

${ }^{15}$ Uma versão anterior desse texto foi apresentada no XVI Congresso Nacional de Estudos Clássicos: Ócio \& trabalho no mundo antigo, realizado em setembro de 2007, no Campus da UNESP-Araraquara/ SP. 
SCODEL, R. Odysseus' dog and the productive household. Hermes. Wiesbaden, vol. 133/ 134, p. 401-408, 2005.

. The removal of the arms, the recognition with Laertes, and narrative tension in the "Odyssey". Classical philology. Chicago, vol. XCIII, n. 1, p. 1-17, 1998.

VERNANT, J-P.; VIDAL-NAQUET, P. Trabalho e natureza na Grécia antiga. In: Trabalho e escravidão na Grécia Antiga. Tradução de Marina Appenzeller. Campinas: Papirus, 1989.

VIDAL-NAQUET, P. O mundo de Homero. Tradução de Jônatas Batista Neto. São Paulo: Companhia das Letras, 2000. 